BRITISH MEDICAL JOURNAL VOLUME $285 \quad 20$ NOVEMBER 1982

\section{Overcoming Isolation}

\section{Research as a solution in the North East}

TIM CARNEY, ALLEN HUTCHINSON

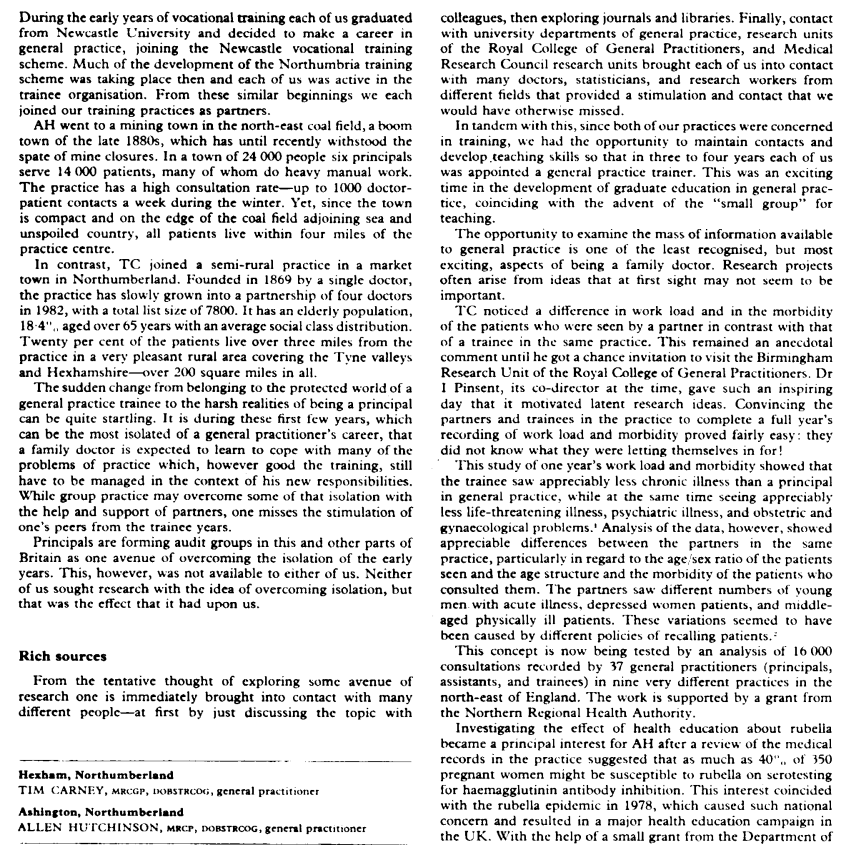

BRITISH MEDICAL JOURNAL VOLUME $285 \quad 20$ NOVEMBER 1982

1473

\section{Shortlisting Trainees}

\section{Democracy reigns in Aberdeen}

DENIS DURNO

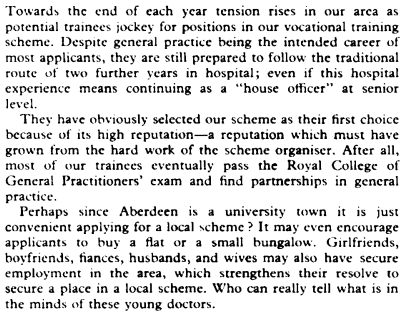

The scheme

The Aberdecn Vocational Training Scheme was established in August 1971 after initiatives were made by the Department
of General Practice, University of Aberdeen, the local faculty of the Royal College of General Practitioners, and other
interested in promoting training in general practice. The scheme is based on tow years in hospptial and one year in genera
practice. The hospital posts comprise six months in acciden
and emergency, two months cach in skins, cyes, and ENT and emergency, two months cach in skins, eyes, and EETT,
periods of training in obstetrics and gynaecology and padediatrics

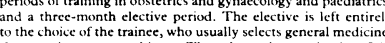
to the choice of the trainec, who usually selects general medicine,
rheumatology, or psychiatry. The schereme has an intake of 12 trainees a year. There is no opportunity to spend an introductory
period in gencral practice. This has been looked at but the timetablc was soo complex to include it.
I can still vividely recall the anxicty of the organisers in $197 /$ I can still vividly recall the anxicty of the organisers in 1971
that thes would have sufficicnt applicants to fill the 12 place
I also still share with Professor Richardson the scars of attemp I also still share with Profecssor Richardson the scars of attemp
ing to get our first group of 12 tranines to establish a selldirected learning group as part of their day-relecese pregramm The department of gencral practice in Aberdeen was responsible
for all aspects of the scheme in its first few years, till a regional

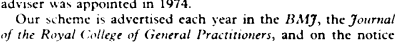

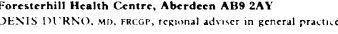

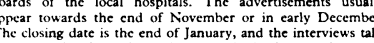

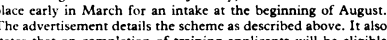

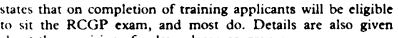

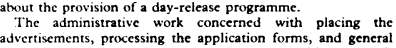

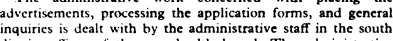

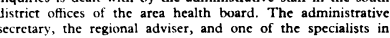
ommunity medicience (Who happens to be be the chatriman of the

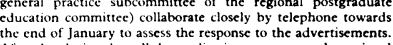

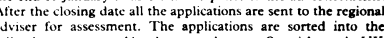

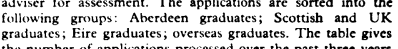

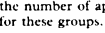

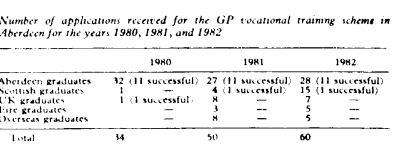

Local graduates clearly have an advantage for selection, but
we arc anxious to identify doctors from other parts of Bribing

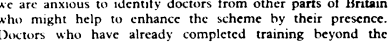

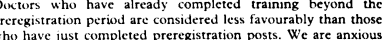

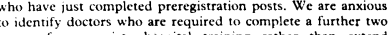

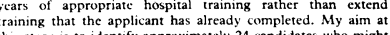

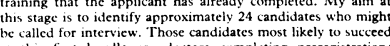

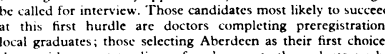

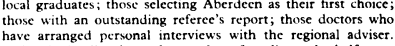

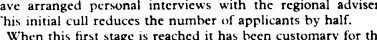

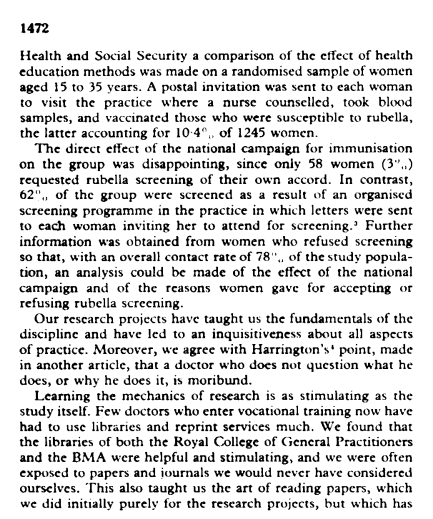

BRTISH MEDICAI JOCRNAL VOLUME $285 \quad 20$ NOVEMBER 1982 become a valuable part of our continuing education-in itself a
method of overceming isolation. method of overceming isolation.
Years of research may be ruined for the want of proper control and planning in the initial stages, and taking the advice of other
professionals concerned in research in the Health Scrvice is
essential in developing an idea. It is of often during this stage that essential in developing an idea. It is often during this stage that
one comes into contact personally with so many other pro-
fessionals from so many specialties of medicine that one finds the most reward.
Finally, writing a research paper taught cach of us, we suspect for the first time, to write English as opposed to notes, and seeing the result puthlished is a reward far in excess of seeing
one's name in print. Publishing research from general practice is paramount if audit groups are to have facts to refer to or is paramo is to develop. Indirectly this leads to overcoming
risolation for all general practitioners by building a common isolation for all general practitions contacts that research brings
knowledge of our work. The contas personally, through reading and writing, not only overcome
issatation but also add a stimulus to life which is an exciting

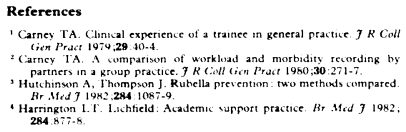

Diary of Urban Marks: 1880-1949

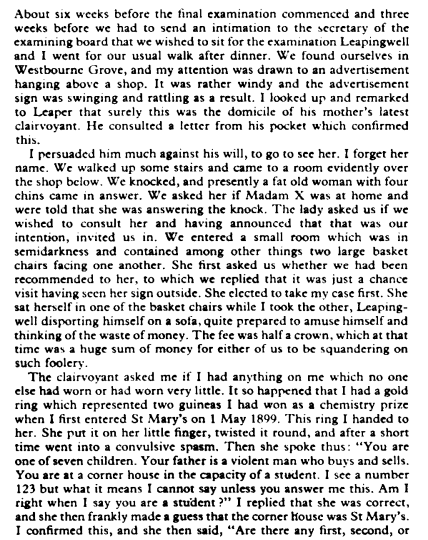

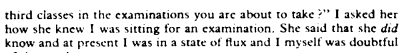
of the result.
"But if there is no classification in the examination then you will be

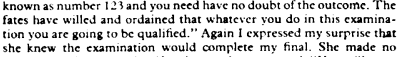

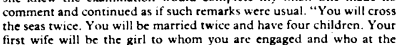
moment is somewhere in the North - $\mathrm{tic}$ cannot be the South since
see a great distance between you and her. She is knitting or mending

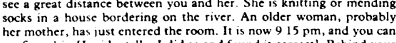
chair $a$ woman who has recently passed over has now anpeared. This
I guess is your thother, and she is holding in her hand $a$ bunch of I guess is your mother, and she is holding in her hand a bunch of
wheat. This signifies that you will never be in want. In fact you are
onc of the lacky ones of this earth, and everything you do will be

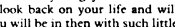
wonder how you got to the postition you will be in then with such
effort on your part. Your stars are certrinly fighting for you."

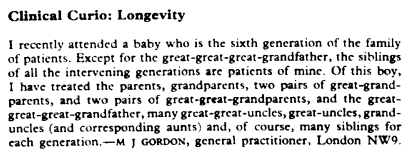

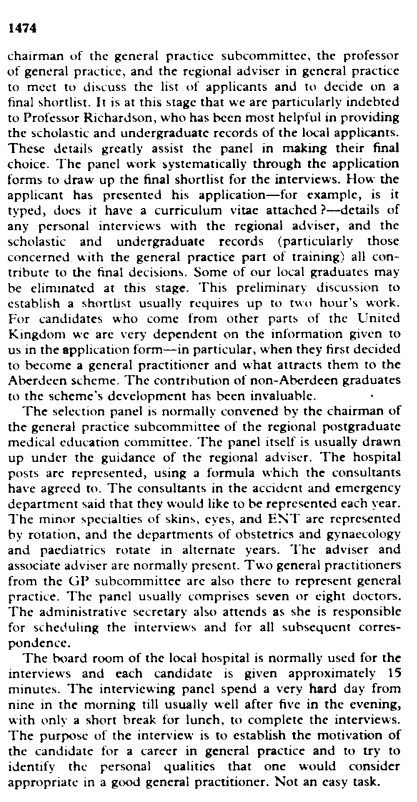

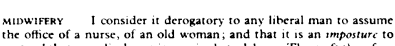

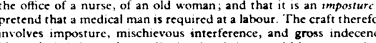

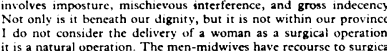

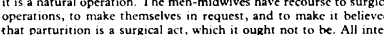

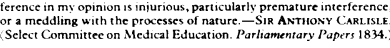

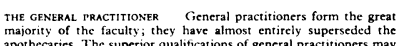

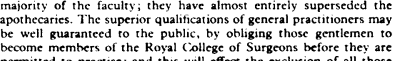

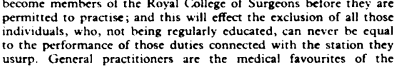

BRITISH MEDICAL JOURNAL VOLUMA $285 \quad 20$ NONEMBRR 1982 Each panel member has a copy of the candidate's application
form with details which include their medical career to date ny special features of their undergraduate training, where
hey did their undergraduate training in gencral practicc, why hey want to train for a career in general practice, their socid It is not necessary for each panel member to ask question
fevery candidate, but he is expected to score the interview

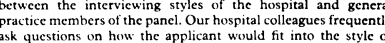
ons often of a closed or the

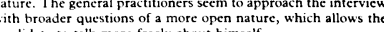
After each candidatere has been interviewed the panel are

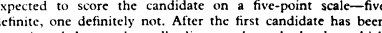

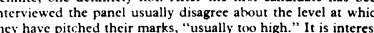
ing that this year we had a candidate who had been interviewed
he year before as our first candidate. The marks allocated to

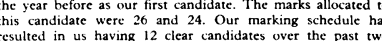

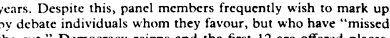
the cut." Democracy reigns and the first 12 arc offered places. Not all successtul candidates accepp appointment, sugessting
that they have becen shopping around to find the scheme that

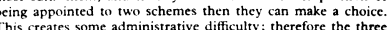
of four unsuccessfui candidates who have just failed to secure palaces are usually kept on a resecrve list till those selected have
accerted the appointment in writing.
It these posts werre nor mally available on the open market for

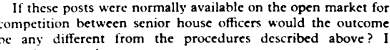
In reviciewng the last five years of the scheme, however,
47 men and 13 women have been appointed and of thess, 39 men and four women have found careers in general practice.
Whether a placement of ust over $700^{\circ}$ in general practice Whether a placement of just over 70 ", in general practice
satisfactory I do not know. Some of the remaining trainces "intend returning to general practice," and even if they do not,
perhaps sheir contritibution to their chosen specialty will be

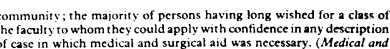

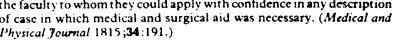

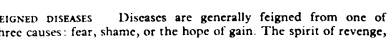

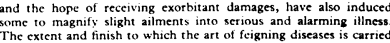

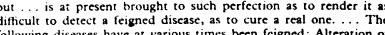

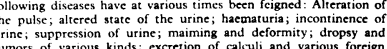

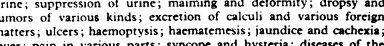

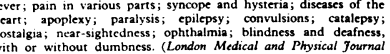

